\title{
Modelagem do plano de permanência e êxito discente: uma proposta para o mapeamento do contexto de evasão
}

\author{
Modeling the stay plan and discent success: a proposal for mapping the evasion context
}

\author{
Modelando el plan de estancia y el éxito del estudiante: una propuesta para mapear el contexto de \\ deserción
}

\section{Resumo}

O estudo apresenta uma proposta para a modelagem e mapeamento de processos acadêmicos, corroborando para a prevenção e identificação das causas de evasão discente, de modo a auxiliar os objetivos do plano de permanência e êxito (PPE) desenvolvido por algumas instituições de ensino. A proposta foi elaborada por meio de reuniões com todos os agentes presentes na instituição alvo da pesquisa, a saber: Equipe de gestão, Docentes, Técnicos Administrativos em Educação, Terceirizados e Discentes. Desta forma, o trabalho tem objetivo de identificar o momento em que o discente inicia um contexto de possível evasão. As reuniões foram devidamente registradas nos sistemas de informação institucionais e, por sua vez, possibilitaram a elaboração, análise e validação do mapeamento de processos, com a identificação do exato momento que o discente inicia um possível contexto de evasão ou retenção, mas também foi revelado um curto intervalo temporal salutar e preventivo que demanda ações específicas para evitar a consolidação da evasão. Ademais, a temática ainda é motivada pela Lei Geral de Proteção de Dados Pessoais (LGPD), visto a existência de dados sensíveis dos discentes e a tramitação dos respectivos processos por diversos setores institucionais, o que demanda uma maior atenção das instituições de ensino para a gestão de seus processos internos.

Palavras-chave: Evasão e retenção acadêmica; Plano de permanência e êxito discente; Mapeamento e modelagem de processos; Gestão por processos; Lei Geral de Proteção de Dados Pessoais (LGPD).

\begin{abstract}
The study presents a proposal for the modeling and mapping of academic processes, supporting the prevention and identification of the causes of student dropout, in order to support the objectives of the permanence and success plan (PPE) developed by some educational institutions. The proposal was elaborated through meetings with all agents present in the target institution of the research, namely: Management team, Faculty, Administrative Technicians in Education, Outsourced Persons and Students. Thus, the work aims to identify the moment when the student starts a context of possible dropout. The meetings were duly registered in the institutional information systems and, in turn, enabled the elaboration, analysis and validation of the process mapping, with the identification of the exact moment when the student starts a possible context of evasion or retention, but it was also revealed a short salutary and preventive time interval that demands specific actions to avoid the consolidation of dropouts. Furthermore, the theme is still motivated by the General Law for the Protection of Personal Data (LGPD), given the existence of
\end{abstract}


sensitive data of students and the processing of the respective processes by various institutional sectors, which demands greater attention from educational institutions for the management of its internal processes.

Keywords: Academic evasion and retention; Plan for permanence and student success; Process mapping and modeling; Process management; General Data Protection Law (LGPD).

\section{Resumen}

El estudio presenta una propuesta para el modelado y mapeo de procesos académicos, apoyando la prevención e identificación de las causas de la deserción escolar, con el fin de apoyar los objetivos del plan de permanencia y éxito (PPE) desarrollado por algunas instituciones educativas. La propuesta se elaboró a través de reuniones con todos los agentes presentes en la institución objetivo de la investigación, a saber: Equipo directivo, Profesorado, Técnicos Administrativos en Educación, Subcontratados y Estudiantes. Así, el trabajo tiene como objetivo identificar el momento en el que el alumno inicia un contexto de posible abandono. Las reuniones fueron debidamente registradas en los sistemas de información institucionales y, a su vez, posibilitaron la elaboración, análisis y validación del mapeo del proceso, con la identificación del momento exacto en que el alumno inicia un posible contexto de evasión o retención, pero también fue reveló un breve intervalo de tiempo saludable y preventivo que demanda acciones específicas para evitar la consolidación de abandonos. Además, el tema sigue motivado por la Ley General de Protección de Datos Personales (LGPD), dada la existencia de datos sensibles de los estudiantes y el procesamiento de los respectivos procesos por parte de diversos sectores institucionales, lo que demanda una mayor atención por parte de las instituciones educativas para la gestión de sus procesos internos.

Palabras clave: Abandono y retención académicos; Plan de permanencia y éxito del estudiante; Mapeo y modelado de processos; Gestión de processo; Ley General de Protección de Datos Personales (LGPD).

\section{Introdução}

A evasão é definida como uma ação de desistir ou abandonar. Em primeiro lugar, a evasão representa uma ideia de fracasso do discente no seu itinerário formativo, mas também impõe um desafio para as mais diversas instituições de ensino, no sentido de melhorar os seus indicadores.

No contexto acadêmico, a evasão tem algum motivo e deve ser devidamente identificado para a possível implementação de medidas de prevenção, com o intuito de proporcionar a continuidade do itinerário formativo do discente. Muitas vezes, o motivo da evasão é para desenvolver uma atividade laboral ou algum outro fator social. Contudo, a evasão escolar é muito problemática e desencadeia uma série de desafios para o estudante e a instituição de ensino (Filho; Araújo, 2017).

Fatores como a retenção ou a falta de uma base sólida no Ensino Fundamental são motivadores para a evasão. Conforme Branco et al (2020), o desafio de manter o discente no seu ambiente acadêmico é um dos problemas do sistema educacional brasileiro e pode ter relações com a vulnerabilidade social do estudante e de seus familiares.

O presente estudo, precipuamente, propõe uma série de ações a serem executadas, através de um mapeamento de processo, que identifica o aluno em contexto de evasão e busca auxiliar o discente a permanecer na instituição, por meio de cursos de extensão, orientação pedagógica, monitoria remunerada ou voluntária, assistência estudantil, atendimento psicológico ou cursos introdutórios, de acordo com a causa da possível evasão.

Portanto, este trabalho tem uma relação direta com as ações integradas entre pesquisa, inovação, extensão, ensino e gestão acadêmica, com o objetivo de identificar o momento em que o discente inicia um contex to de possível evasão, assim como apresentar o momento ideal para a adoção das medidas necessárias a fim de evitar a sua consolidação.

Além de incentivar a devida coleta e arquivo de informações importantes para a formação de um banco de dados que, por sua vez, poderá auxiliar nas tomadas de decisão da equipe de gestão, assim como na elaboração de relatórios para auditorias internas e externas. A temática ainda é motivada pela lei geral de proteção de dados pessoais (LGPD), visto a existência de dados sensíveis dos discentes e a tramitação dos respectivos processos por diversos setores institucionais, o que demanda uma maior atenção das instituições de ensino para a gestão de seus processos internos. 
Ademais, existe a expectativa da apresentação de um conjunto de atividades através do mapeamento de processos, em consonância com a atual implementação da lei geral de proteção de dados pessoais (LGPD), com o intuito de identificar todo o ciclo de vida e de tramitação dos dados sensíveis dos discentes e de todos os setores que têm acesso aos referidos dados, constituindo um objetivo intrínseco da LGPD.

A partir do presente estudo, surgem os seguintes questionamentos: Como identificar o contexto da possível evasão ou retenção discente ainda no seu estado inicial e adotar as ações necessárias para evitar a sua consolidação? Como identificar o momento mais oportuno para implementar medidas capazes de evitar a iminente evasão ou retenção? Como promover a integração entre os setores acadêmicos que desempenham ações específicas contra evasão e retenção, de maneira a corroborar com a Lei Geral de Proteção de Dados Pessoais (LGPD)?

Ainda, como forma complementar, são apresentados instrumentais que facilitam a compreensão e registros de dados nos sistemas institucionais, assim como um resumo das atribuições de todos os setores presentes no mapeamento de processos.

\section{Evasão e Retenção Acadêmica}

A evasão acadêmica é um problema enfrentado por todas as instituições de ensino, seja pública ou privada. Segundo Lino (2020), são muitos os fatores que contribuem para a evasão escolar, ou seja, para a não finalização de alguma etapa da educação dos alunos.

Fritsch e Vitelli (2016) discorrem também que a evasão escolar está relacionada com a perda de estudantes iniciantes em seus cursos, mas que não concluem essa etapa por diversos motivos internos e externos às instituições. Costa e Santos (2017) ratificam que a evasão escolar deve ser tratada como um fenômeno contínuo e que pode ser originada por diversos fatores, sejam acadêmicos, sociais, culturais, entre outros.

Um dos motivos da consolidação da evasão é a retenção, que trata-se da preservação do discente em um mesmo nível escolar. Segundo Gil (2018), a retenção acadêmica é caracterizada pela decorrência de reprovação do aluno, visto que determina a impossibilidade do discente seguir no fluxo normal de um nível inferior ao outro superior. Portanto, a retenção e evasão causam problemas para os alunos, instituições de ensino e ao desenvolvimento da educação no Brasil. Com isso, fazse necessário realizar um planejamento de ações de combate a esses fenômenos.

Conforme Filho e Araújo (2017) esses fenômenos prejudicam todos os envolvidos no processo educacional, então se faz necessário elaborar um planejamento para a minimizar as ocorrências, bem como a mitigação dos impactos originados com a retenção e evasão.

As instituições de ensino têm buscado oportunizar o acesso à educação para todos. Contudo, com o objetivo de identificar as causas e projetar caminhos para o combate à evasão e retenção, observa-se a elaboração de documentos específicos com a participação da comunidade acadêmica, como os Planos Estratégicos de Permanência e Êxito (PPE), que têm como objetivo promover, por meio de ações sistêmicas e locais articuladas, a continuidade do itinerário formativo dos estudantes (Vieira; Gallindo; Cruz, 2017).

Contudo, como forma de contribuir com o Plano de Permanência e Êxito, foram estudadas, elaboradas e aprimoradas metodologias inovadoras no âmbito do ensino, mas com bastante aplicabilidade no âmbito das engenharias, com o objetivo de identificar o início do contexto de evasão discente e traçar medidas que evite a sua consolidação. 


\section{Mapeamento e modelagem de processos}

Processo é o termo que se dá a um conjunto de atividades, com início e fim definidos. O autor Lima (2017, p. 14) afirma que: "Os processos recebem entradas e geram suas saídas, que se iniciam e terminam com o cliente externo".

Existem nas organizações um número elevado de processos, por isso se faz necessário o seu gerenciamento. Uma forma de gerir essas atividades é por meio da modelagem. No mapeamento de um processo, pode-se obter uma visão completa das atividades a serem executadas de forma sequencial, além da informação de como o processo deve ser realizado na instituição.

Lima (2017) ratifica que essa representação de modelagem dos processos é essencial para a compreensão dos mesmos, pois esse desenho apresenta não só onde o processo inicia e finaliza, mas também os responsáveis pela execução e os setores ou departamentos envolvidos.

Segundo Castellanelli (2016), a gestão por processos pode resultar grandes resultados para a organização, através da modelagem dos processos e sua melhoria contínua, de acordo com as expectativas organizacionais. Logo, a modelagem pode ser apresentada em forma de fluxogramas, mapa ou diagrama.

Conforme Britto (2016), o Gerenciamento de Processos de Negócio requer uma mudança da mentalidade da organização, pois através do gerenciamento dos processos as instituições irão reconhecer seus processos e vislumbrar a possibilidade de crescimento.

\subsection{Os processos existentes nas instituições de ensino}

Nas instituições de ensino, existe um grande fluxo de processos, tais como: matrículas, elaboração de horários de professores, criação de turmas, atividades de combate à evasão e retenção, entre outros. Um exemplo é o processo de matrícula que envolve o setor de controle acadêmico, como mostra a Figura 1.

O processo apresentado na figura 1 é simples e de fácil compreensão, porém em todas as organizações existem processos simplificados e mais complexos. O mapeamento de processo pode ajudar seus colaboradores a executá-lo com mais eficiência.

Atualmente, as instituições públicas e privadas, em busca de conhecer seus processos e gerenciá-los, de forma adequada, encontram no mapeamento de processos a solução. Conforme Carvalho e Sousa (2017), a Universidade Federal do Rio Grande do Sul (UFRGS) é referência em gestão de processos para as instituições de ensino superior.

Figura 1: Processo de matrícula.

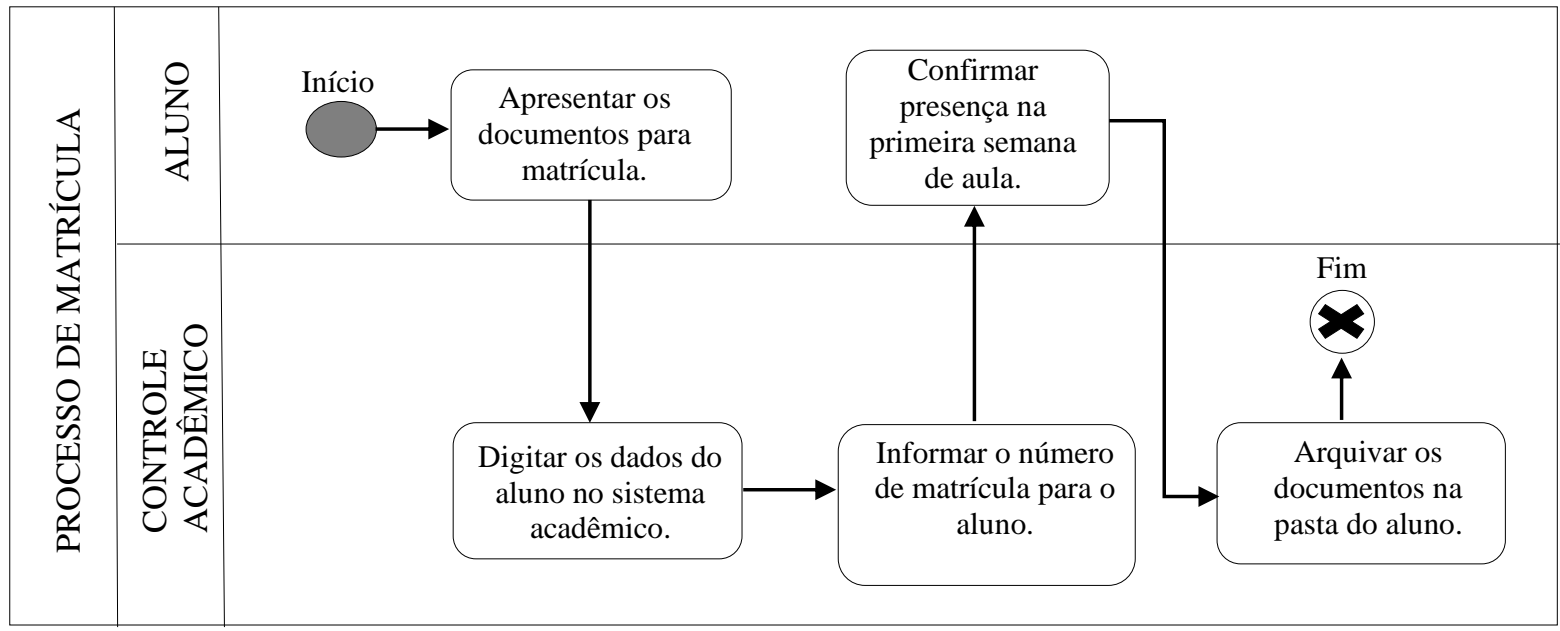

Fonte: Autores (2021). 


\subsubsection{Ferramentas para mapeamento e modelagem de processos}

A modelagem de processos necessita de um software específico para a sua elaboração. A notação empregada é o Business Process Model and Notation (BPMN) que trata de ícones padronizados e facilitadores do entendimento do usuário.

Conforme Esguícero (2020), o gerenciamento de processos de negócios traz a união da gestão com a tecnologia, através de softwares que utilizam a notação Business Process Model and Notation (BPMN). Os referidos softwares executam a modelagem por meio de fluxogramas com todas as etapas de um processo. Dessa maneira, o mapeamento é capaz de facilitar o entendimento de todos os envolvidos no processo. A partir da importância dessa modelagem para as organizações, apresentam-se alguns softwares que utilizam o método BPMN, a saber: Bizagi Modeler, Heflo, BPMN.io, Aris Express.

De acordo com Araújo et al (2015), com a importância da gestão por processos surgiram muitas ferramentas de modelagens, fortalecendo o controle dessas atividades. Uma dessas ferramentas é o Bizagi Modeler, este software disponibiliza download gratuito e utiliza a notação BPMN. A ferramenta foi a utilizada para o desenvolvimento da metodologia do presente estudo.

\subsubsection{A Gestão de processos nas instituições de ensino}

Nas instituições de ensino são muitos os processos a serem geridos e executados. Isso ocorre, segundo Silva et al (2015), pois existem modelos complexos e burocráticos, os quais formam um aparato avesso a mudanças, configurando um panorama de "perenidade institucional" (2015, p. 103). Para os mesmos autores, os gestores das instituições devem pensar em novas técnicas de gestão.

Conforme Repa e Bruckner (2015), a gestão de processos é capaz de administrar o ciclo de vida dos processos da organização, incluindo uma orientação sobre a sua execução, revisão e possibilidades de melhorias. Além disso, segundo Entringer, Ferreira e Nascimento (2021), a utilização da gestão por processos possibilita a uniformização e padronização dos processos organizacionais que estão cada vez mais complexos.

Outro atrativo do tema de gestão de processos para as instituições de ensino é o conhecimento total do processo, que tem o intuito de promover a celeridade necessária para atendimento aos cidadãos, além de: evitar redundâncias, utilizar com mais eficiência os recursos, desburocratização, nivelamento de informações e envolvimento da equipe, identificação e documentação dos processos existentes na instituição, oportunidade de melhoria contínua para fluxos de processos e tomada de decisão. Essas vantagens são capazes de inovar e trazer mudanças satisfatórias para as instituições.

De acordo com Cajuela e Galina (2020), uma das vantagens da gestão por processos é questão da uniformização e nivelamento das informações entre os colaboradores. Além disso, segundo Noveli e Arbertin (2017), caso a organização tenha objetivo de maximizar a capacidade de monitorar as atividades e os participantes durante a execução do processo, poderá promover o seu gerenciamento de processos através da automação.

Paiva et al (2017) ratificam o exposto, pois acreditam que a gestão de processos é uma estratégia que possui inúmeras ferramentas capazes de contribuir para a melhoria da qualidade do serviço prestado para a sociedade.

\subsubsection{Lei Geral de Proteção de dados pessoais (LGPD)}

A Lei Geral de Proteção de Dados Pessoais (LGPD), de n 13.709/18, cria uma segurança jurídica que visa uniformizar práticas para promover a proteção de dados pessoais de todo cidadão que esteja no Brasil. A lei explica que é necessário um tratamento de dados para qualquer operação e de acordo Velho (2020, p. 09): "Eles também poderão pedir aos agentes de tratamento a confirmação de seus dados, o acesso a eles, sua correção, anonimização, bloqueio, eliminação e portabilidade". 
Todos os dados pessoais devem seguir critérios definidos pela LGPD, porém, a lei traz mais recomendações para o tratamento de dados sobre crianças e adolescentes. Segundo a Lei n ${ }^{\circ}$ 13.709/18:

Art. 14. O tratamento de dados pessoais de crianças e de adolescentes deverá ser realizado em seu melhor interesse, nos termos deste artigo e da legislação pertinente.

$\S 1^{\circ} \mathrm{O}$ tratamento de dados pessoais de crianças deverá ser realizado com o consentimento específico e em destaque dado por pelo menos um dos pais ou pelo responsável legal (BRASIL, 2018).

A referida legislação ainda define o que são considerados dados "sensíveis":

Art. $5^{\circ}$ Para os fins desta Lei, considera-se:

[...] II - dado pessoal sensível: dado pessoal sobre origem racial ou étnica, convicção religiosa, opinião política, filiação a sindicato ou a organização de caráter religioso, filosófico ou político, dado referente à saúde ou à vida sexual, dado genético ou biométrico, quando vinculado a uma pessoa natural (BRASIL, 2018).

Conforme Divino (2019), a lei geral de proteção de dados pessoais promoveu a segurança de dados à pessoa física, sobretudo no seu relacionamento com empresas e instituições. A lei visa conservar a exposição de informações dos sujeitos em todos os ambientes, inclusive o virtual. A legislação ainda determina quais os documentos e dados podem ser divulgados em relações contratuais entre o sujeito e a empresa com quem ele está se relacionando.

Segundo Cruz (2021), com a LGPD as instituições de ensino precisam ter controle dos processos internos para garantir a segurança dos dados sensíveis dos alunos e seus familiares, professores e demais colaboradores. No caso das instituições de ensino que lidam com um grande volume de dados pessoais sensíveis de alunos, foi criado um instrumental para os relatórios previstos em algumas etapas da proposta de mapeamento de processo do presente estudo, de forma que os discentes em contexto de evasão serão identificados apenas pelo número de matrícula, o que preserva a identificação do aluno, consoante com a legislação em vigor.

\section{Metodologia}

As pesquisas exploratórias, precipuamente, disponibilizam dados sobre o foco alvo do trabalho de pesquisa, com objetivos e formulações de hipóteses traduzidas na pergunta norteadora. Dessa forma, o estudo de caso é caracterizado por uma necessidade de estudo detalhado, com possibilidade de mais de 1 (um) objeto e que necessite um trabalho amplo, inviável de ser praticado em outros delineamentos de uma pesquisa (GIL, 2018). Além disso, a realização do presente estudo demandou avaliações de cunho qualitativo e quantitativo.

Gil (2018) classifica as fontes de pesquisa documental em dois grupos. O primeiro grupo destaca os documentos que não receberam nenhum tipo de tratamento, como arquivos de órgãos públicos (digitais e físicos), regulamentos, ofícios e boletins. Já o segundo grupo é composto por documentos que já foram analisados, tais como relatórios de pesquisa, notas técnicas, entre outros.

Nesse ínterim, foi observada a necessidade de uma pesquisa bibliográfica, por meio de livros, de artigos científicos e de dissertações, no sentido de propiciar uma fundamentação teórica sobre a problemática. Ademais, também se verificou uma pesquisa documental, com a coleta de informações inerentes ao ambiente institucional.

Para Yin (2015), o estudo de caso é sugerido quando são utilizados os termos "como" e "por que" nas perguntas norteadoras da pesquisa, além de não exigir controle sobre eventos comportamentais e manter o foco nos eventos contemporâneos.

Dessa maneira, o estudo em questão consiste em identificar os casos de evasão discente ainda no seu estado inicial, com a sugestão de ações eficazes a serem executadas no momento mais oportuno e com o sentido de evitar a sua consolidação, 
de forma a corroborar com a lei geral de proteção de dados pessoais. Nesse contexto, segue o método utilizado com as referidas etapas executadas numa instituição de educação profissional e tecnológica.

\subsection{Método proposto}

As etapas da pesquisa são representadas na Figura 2, conforme segue:

Figura 2: Método utilizado na pesquisa.

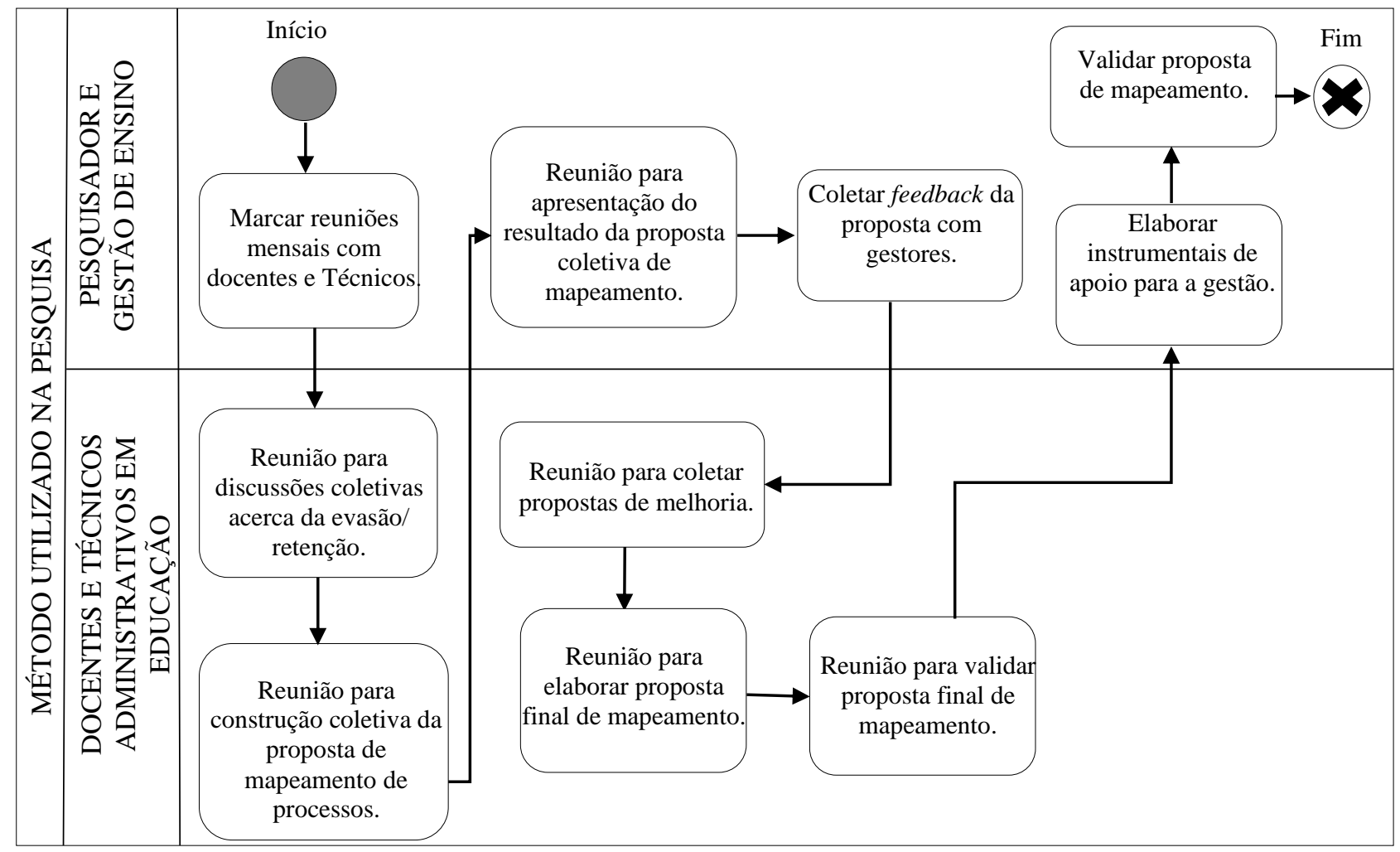

Fonte: Autores (2021).

Inicialmente, foram realizadas reuniões mensais com a equipe da instituição de ensino profissional e tecnológica, a saber: docentes, técnicos administrativos em educação, terceirizados, discentes e a equipe de gestão. As reuniões tinham como objetivo cronologicamente, a saber:

1) Provocar a discussão sobre a necessidade de melhoria dos indicadores de permanência e êxito discente na instituição;

2) Construção coletiva da proposta de um mapeamento de processos com ações necessárias com o objetivo na melhoria dos indicadores de permanência e êxito discente;

3) Apresentação da primeira proposta de mapeamento de processos para coleta de críticas construtivas no sentido de aprimorar o trabalho;

4) Validação do mapeamento de processos perante a equipe, a fim de viabilizar a padronização de ações e sua devida operacionalização.

5) Elaborar instrumentais de apoio para a gestão, a partir da validação do mapeamento processos.

\section{Resultados e Discussões}

Segue a proposta de mapeamento de processos validada por toda a equipe em reunião específica, conforme Figura 3: 
Figura 3: Mapeamento de processos.

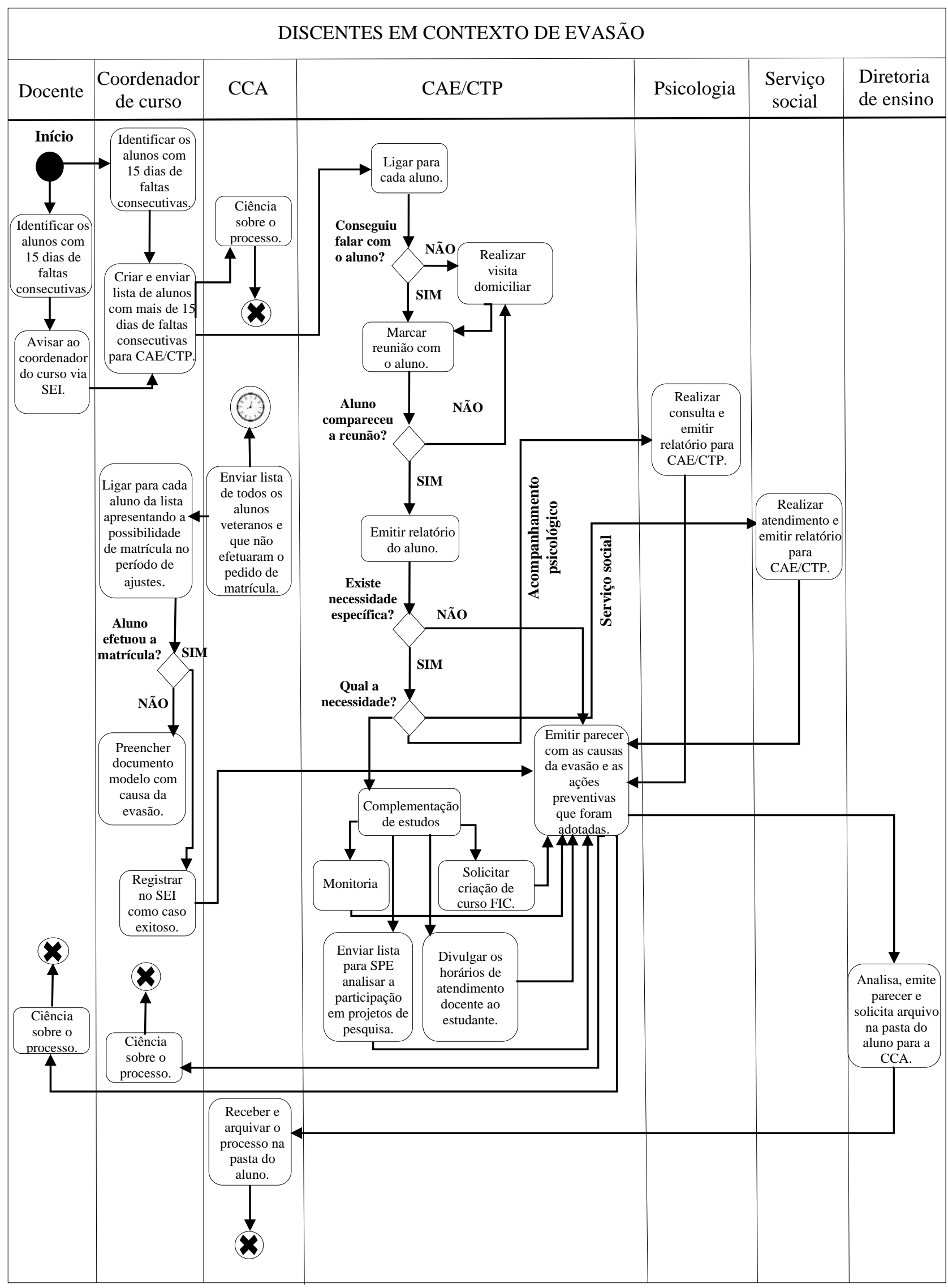

Fonte: Autores (2021). 
Sobremaneira, o mapeamento de processos, conforme Figura 3, apresenta um aspecto preventivo, pois além de propor um método para identificar os casos de potencial evasão acadêmica, direciona os trabalhos dos setores acadêmicos para o público alvo discente com o maior potencial evasor, sugerindo medidas específicas para o contexto de cada aluno no curto intervalo temporal que mais apresenta possibilidade do retorno do discente para suas atividades acadêmicas.

Outrossim, o fato pode ser percebido por meio da sugestão da implementação de atendimentos aos discentes pelos setores específicos a serem demandados pela coordenação técnico- pedagógica e com a devida identificação do agente causador da possível evasão, já registrado em relatório prévio, seguido do respectivo encaminhamento para as demais áreas de competência, como: assistência de alunos, psicologia, extensão e pesquisa.

Diante disso, o mapeamento ainda ressalta uma última possibilidade de ação, no caso do discente que não correspondeu às tentativas de contato ou que permaneceu inerte após os atendimentos prestados pelos setores - por meio da proposta da realização de um contato com o referido aluno - desta vez já reprovado por faltas, ou seja, em condição de retenção acadêmica, mas ainda não evadido. O referido contato, é sugerido no momento exatamente anterior ao período de ajustes de matrículas, uma vez que o discente ainda não realizou pedido de matrícula em nenhum componente curricular. Dessa forma, o mapeamento sugere o início de um processo interno de identificação e contato com o referido estudante, envolvendo o setor de controle acadêmico e coordenação de curso que, por sua vez, informa a possibilidade de matrícula para o aluno, por vezes desconhecida pelo próprio discente.

Esse procedimento, que pode ser executado por meio do acesso ao sistema acadêmico ainda no período de ajustes, evita a consolidação da iminente evasão. Caso não tenha sucesso, a coordenação de curso já realiza o registro definitivo da causa da evasão informada pelo próprio discente, conforme instrumental utilizado para o referido registro e disposto ao final do presente trabalho.

O estudo ainda oportuniza a reunião de todos os documentos que corroboram com o plano de permanência e êxito institucional, emitidos pelos setores vinculados ao ensino ou pelas coordenações de curso. O mapeamento das atividades, para a devida identificação e encaminhamento de alunos em contexto de evasão, apresenta uma proposta de análise quantitativa acerca dos dados que auxiliam a gestão na execução de ações preventivas, a partir da oportunidade do intervalo temporal que o discente ainda tem vínculo institucional, ou seja, quando o aluno ainda não está reprovado por faltas, mas já apresenta ausências seguidas que demonstram um potencial e iminente contexto de evasão e/ou retenção.

Entre as atividades do fluxo de trabalho para identificação dos discentes em contexto de evasão, destacam-se:

- Docentes: Identificar alunos com 15 dias de faltas consecutivas; Listar e informar para a coordenação do curso os alunos que estão na referida situação.

- Coordenações de cursos: identificar e enviar lista dos alunos com 15 dias de faltas consecutivas para o setor técnico-pedagógico e assistência estudantil; estabelecer contato com os alunos contidos na listagem enviada pelo setor de registro acadêmico que contém os discentes que ainda não efetuaram matrículas antes do início do período de ajustes.

- Coordenação técnico-pedagógica (CTP): estabelecer contato com alunos com 15 dias de faltas consecutivas; marcar reunião com alunos ou realizar visita (conforme mapeamento); emitir relatório do aluno solicitando possíveis acompanhamentos especializados (psicológico, assistência social ou complementação de estudos); emitir parecer com as causas de evasão e as ações preventivas que foram adotadas.

- Setor de psicologia: realizar consultas solicitadas pelo setor técnico-pedagógico; emitir relatório para assistência estudantil e setor técnico- pedagógico. 
- Coordenadoria de assistência estudantil (CAE): realizar atendimentos solicitados pelo setor técnicopedagógico; emitir relatório para setor técnico- pedagógico.

- Setor de pesquisa e extensão (SPE): viabilizar oferta de cursos de formação inicial e continuada (FIC), a partir da solicitação do setor técnico- pedagógico; encaminhar possíveis participações de alunos em projetos de pesquisa.

- Coordenação de controle acadêmico (CCA): enviar listagem para a coordenação de curso com os alunos que ainda não efetuaram matrícula antes do período de ajustes.

- Direção de ensino (DE): analisar relatório; emitir parecer; solicitar para o setor de registro acadêmico o arquivamento do relatório na pasta do aluno.

Assim, a sugestão de ações interdependentes a serem executadas pelos diversos setores acadêmicos, propicia uma sinergia salutar para o desenvolvimento sistêmico dos trabalhos no âmbito do combate à evasão e retenção, além de fomentar a geração de relatórios específicos que disponibilizam um histórico das medidas implementadas por toda a instituição, importantes para os casos de auditoria interna ou externa, pois oportuniza a devida apresentação das respectivas ações preventivas e as justificativas para os casos já consolidados de evasão. Além de facilitar a tomada de decisão por meio da disponibilidade de registros, com a formação de um banco de dados condizente ao contexto específico institucional.

\section{Considerações Finais}

A partir da proposta de mapeamento de processos, foi possível identificar o contexto da possível evasão ou retenção discente ainda no seu estado inicial, a partir das quantidades de faltas contínuas dos discentes, assim como elencar as ações necessárias de cada setor para evitar a consolidação da evasão, a saber: assistência estudantil, setor técnico- pedagógico, pesquisa, extensão, ensino e gestão acadêmica. Primordialmente, foi identificado o momento mais oportuno para implementar medidas capazes de evitar a consolidação da iminente evasão, com destaque para o período entre a prématrícula e os ajustes. Com a proposta de integração sistêmica presente no mapeamento de processos, foi possível prever todo o caminho dos dados pessoais e sensíveis dos discentes, de modo a corroborar com a lei geral de proteção de dados (LGPD).

Os desafios, sobretudo, já esperados em estabelecer uma cultura de gestão por processos contraditória ao status quo, além da necessidade de integrar sistemas acadêmicos para a extração e envio de dados específicos, ficaram evidentes durante a elaboração dos trabalhos. Contudo, foram minimizados com a integração e colaboração da equipe. Mediante o exposto, ressalta-se a vantagem da melhoria do fluxo de informações e monitoramento contínuo dos possíveis casos de evasão, o que facilitou os trabalhos com o ensino remoto imposto pelas restrições sanitárias oriundas da pandemia (Covid-19), sendo fundamental para a redução das taxas de evasão.

Ainda como sugestões para pesquisas futuras, destaca-se a prática de gestão por processos com a implantação contínua de ferramentas de gestão, como o gráfico de Gantt que, por sua vez, apresenta todas as tarefas a serem realizadas e sua sequência; além do responsável para a execução e do tempo disponível com o caminho crítico das respectivas atividades. Ademais, destaca-se, a possibilidade da implantação de indicadores estratégicos, com a possível adoção de métricas para análise de desempenho operacional, a partir da aplicação do Business Intelligence (BI). 
Research, Society and Development, v. 10, n. 17, e178101724377, 2021

(CC BY 4.0) | ISSN 2525-3409 | DOI: http://dx.doi.org/10.33448/rsd-v10i17.24377

\section{Referências}

Araújo, R. T. S., Araújo, M. E. S., Medeiros, F. N. S. \& Barroso, G. C. (2015). Modelagem de um sistema de gestão na Educação a Distância no Brasil utilizando redes de Petri Coloridas. Revista chilena de ingeniería. 23(1), 145- 58. DOI: http://dx.doi.org/10.4067/S0718-33052015000100016

Baggi, C. A. S. \& Lopes, D. A. (2011). Evasão e avaliação institucional no ensino superior: uma discussão bibliográfica. Avaliação: Revista da Avaliação da Educação Superior. 16(2), 355-74. DOI: 10.1590/S1414-40772011000200007.

Branco, E. P., Adriano, G., Branco, A. B. G. \& Iwasse, L. F. A. (2020). Evasão escolar: desafios para permanência dos estudantes na educação básica. Revista Contemporânea de Educação. 15(34), 133-55. DOI: https://doi.org/10.20500/rce.v15i34.34781.

Brasil. (2018). Lei Geral de Proteção de Dados Pessoais. Lei n. 13.709, de 14 de agosto de 2018. http://www.planalto.gov.br/ccivil_03/_ato20152018 /2018/l ei/L13709.html.

Britto, G. C. (2016). Guia para formação de analistas de processos: um guia fundamental para a implantar o Business Process Management. Ed. Bookess.

Cajuela, A. R. \& Galina, S. V. R. (2020). Processos em Relacionamentos Interorganizacionais para Desenvolvimento de Capacidade de Absorção em Startups. Revista de Administração Contemporânea. 24(6), 550-66. DOI: 10.1590/1982-7849rac2020180329.

Carvalho, K. A., \& Sousa, J. C. (2017). Gestão por Processos: Novo Modelo de Gestão para as Instituições Públicas de Ensino Superior. Revista Administração em Diálogo, 19(2), 1-18. DOI: https://doi.org/10.20946/rad.v19i2.25298.

Castellanelli, C. A. (2016). Gestão por processos nas organizações públicas: aplicação de um modelo em uma instituição federal de ensino superior. Revista espacios. 37(27), 9. https://www.revistaespacios.com/a16v37n27/16372710.html.

Costa, R. L., \& Santos, J. C. A. (2017). Evasão em cursos técnicos a distância. Educar em revista, 33(66), 241-56. DOI: 10.1590/0104-4060.50700.

Cruz, Danielle da Costa Santos. (2021). A Lei Geral de Proteção de Dados Pessoais (LGPD): Contribuições sobre o uso e proteção de dados para as Instituições de ensino. 2021. 36p. Trabalho de conclusão de curso (Graduação em Sistema de Informação) - Instituto Ciberespacial do Curso de Sistema de Informação, Universidade Federal Rural da Amazônia, Belém, Brasil.

Divino, S. B. S. (2019). Reflexiones escépticas, principiológicas y económicas sobre el consentimiento necesario para la recolección y tratamiento de datos. Derecho, 83, 179-206. DOI: http://dx.doi.org/10.18800/derechopucp.201902.006.

Entringer, T. C., Ferreira, A. S., \& Nascimento, D. C. O. (2021). Comparative analysis of the main business process modeling methods: a bibliometric study. Gestão \& Produção, 28(2). DOI: 10.1590/1806-9649-2020v28e5211.

Esguícero, F. J. (2020). Framework aplicado a modelagem de processos no gerenciamento municipal dos resíduos da construção civil. 216p. Tese (Doutorado em Engenharia de Produção) - Faculdade de Engenharia de Bauru, Universidade Estadual Júlio de Mesquita Filho, São Paulo, Brasil.

Fritsch, R., \& Vitelli, R. F. (2016). Evasão escolar na educação superior: de que indicador estamos falando?. Estudos em Avaliação Educacional. 27(66), 908-37. DOI: 10.18222/eae.v27i66.4009.

Filho, R. B. S., \& Araújo, R. M. L. (2017). Evasão e abandono escolar na educação básica no Brasil: fatores, causas e possíveis consequências. Educação Por Escrito. 8(1), 35-48. DOI: 10.15448/2179-8435.2017.1.24527.

Gil, A. C. (2018). Como elaborar projetos de pesquisa. Atlas.

Gil, N. L. (2018). Reprovação escolar no Brasil: história da configuração de um problema político- educacional. Revista Brasileira de Educação. 23. DOI: $10.1590 / \mathrm{S} 1413-24782018230037$.

Lima, Fabio Uchôas de. (2017). Processos Organizacionais. 31p. https://www2.unifap.br/furtado/files/2017/04/Processos_Organizacionais_1.pdf.

Lino, E. R. O. (2020). A problemática da Evasão Escolar: uma revisão bibliográfica integrativa. 42p. Monografia (Licenciatura em Biologia) - Escola de Ciências Agrárias e Biológicas, Pontifícia Universidade Católica de Goiás, Goiânia, Brasil.

Noveli, M., \& Albertin, A. L. (2017). Um estudo da virtualização de processos: o uso de mundos virtuais com foco em ensino-aprendizagem. Revista Brasileira de Educação [online]. 22(71). DOI: 10.1590/S1413-24782017227151.

Paiva, M. B. M., Feitosa, P. P. B., Cabral, A. C. A., \& Santos, S. M. (2017). Barreiras e facilitadores na gestão de processos de trabalho em Instituição Federal de Ensino Superior. Revista Gestão Universitária na América Latina. 10(4), 47-71, Edição Especial. DOI: 10.5007/1983-4535.2017v10n4p47.

Pereira, M.C. (2019). Evasão escolar: causas e desafios. Revista Científica Multidisciplinar Núcleo do Conhecimento. 01(02), 36-51.

Repa, V., \& Bruckner, T. (2015)Methodology for Modeling and Analysis of Business Processes (MMABP). Journal of Systems Integration. 6, 17-28. DOI: http://dx.doi.org/10.20470/jsi.v6i4.243

Silva, T., Pereira, M. F., Melo, P. A., \& Costa, A. M. (2015). De faculdade a campus: efeitos da criação de uma universidade em sua comunidade acadêmica. Revista Reuna, 20(1), 99-116.

Velho, R. (2020). Em vigor a partir de agosto, implementação da Lei Geral de Proteção de Dados ainda enfrenta desafios. Ciência e Cultura, 72(2), 09-11. DOI: $10.21800 / 2317-66602020000200004$.

Vieira, A. C. F., Gallindo, E. L., \& Cruz, H. A.(2017). Plano estratégico para permanência e êxito dos estudantes do IFCE. Fortaleza: IFCE. https://ifce.edu.br/proen/ensino/plano-de-permanencia-e-exito.pdf.

YIN, R. K. (2015). Estudo de caso: planejamento e métodos. Porto Alegre: Bookman. 